\title{
Towards efficient use of noble metals via exsolution exemplified for CO oxidation
}

\author{
Chenyang Tang, ${ }^{a}$ Kalliopi Kousi, ${ }^{* a}$ Dragos Neagu, ${ }^{* a}$ José Portolés, ${ }^{\text {a }}$ Evangelos I. Papaioannou ${ }^{\mathrm{a}}$ and \\ lan S. Metcalfe*a

\begin{abstract}
Many catalysts and in particular automotive exhaust catalysts usually consist of noble metal nanoparticles dispersed on metal oxide supports. While highly active, such catalysts are expensive and prone to deactivation by sintering and thus alternative methods for their production are being sought to ensure more efficient use of noble metals. Exsolution has been shown to be an approach to produce confined nanoparticles, which in turn are more stable against agglomeration, and, at the same time strained, displaying enhanced activity. While exsolution has been extensively investigated for relatively high metal loadings, it has yet to be explored for dilute loadings which is expected to be more challenging but more suitable for application of noble metals. Here we explore the substitution of Rh into an A-site deficient perovskite titante aiming to investigate the possibility of exsolving from dilute amounts of noble metal substituted perovskites. We show that this is possible and in spite of certain limitations, they still compete well against conventionally prepared samples with higher apparent surface loading when applied for CO oxidation.
\end{abstract}

\section{Introduction}

Noble metals dispersed on metal oxide supports are being used to catalyse a wide range of reactions. One of the most important applications of noble metals is in automotive exhaust control which employs $60 \%$ of the annual production of noble metals, including $\mathrm{Pt}, \mathrm{Pd}$ and $\mathrm{Rh}^{1}$. While very active, they are still subject to deactivation over time (e.g. by sintering, poisoning), and only small amounts of noble metals can be recovered from the used catalysts ${ }^{2}$. A lot of effort has been made to replace noble metal catalysts, or at least partly substitute them with base metals or their oxides (e.g., $\mathrm{Co3O} 4, \mathrm{CuO}$ and $\mathrm{NiO}$ ) ${ }^{3,4}$, spinel materials (e.g., copper chromite, cobalt manganite $)^{5}$ or perovskites ${ }^{6}$, but up to now their replacement without compromising activity remains challenging. Therefore, there is a critical need to develop means to more efficiently use noble metals while at the same time ensuring longer lifetime for the catalysts.

One catalyst fabrication method that could allow more efficient use of noble metals is redox exsolution from perovskite oxides. In this method, the active metal species are substituted on the $\mathrm{B}$-site of a perovskite oxide host $\left(\mathrm{ABO}_{3}\right)$ under oxidizing conditions, and subsequently emerged from the lattice, under reducing conditions, at high temperature, to form metal nanoparticles. Exsolution has been shown to be an approach to produce more durable catalysts. When exolution is designed to be reversible (stoichiometric perovskite composition, $\mathrm{ABO}_{3}$ ), agglomeration may be mitigated by periodically re-dispersing the particles by redox cycling, thus dissolving and then re-

a. School of Engineering, Newcastle University, Merz Court, Newcastle upon Tyne NE1 TRU, U.K. exsolving the particles ${ }^{7}$. When exsolution is irreversible (A-site deficient perovskite composition, $\mathrm{A}_{1-\alpha} \mathrm{BO}_{3}$ ), exolved particles are socketed, which endows them with enhanced stability against agglomeration ${ }^{8}$, and strain resulting in higher catalytic activity ${ }^{9,10}$.

Exsolution of noble metals has been demonstrated before but only for relatively high loadings $7,11-14$ which are not costeffective for larger scale catalytic application (Fig. 1). In order to use noble metals more efficiently, it is important to be able to exsolve from perovskites containing dilute substitution levels of noble metals. However, this is expected to be very challenging due to thermodynamic and kinetic reasons. That is, at low substitution levels, the noble metal ions would interact more strongly with the perovskite lattice, essentially increasing the thermodynamic requirements for them to exsolve ${ }^{15}$. At the same time, at dilute levels, diffusional processes required to supply exsolvable ions to the surface would have larger impact on particle growth and as a consequence on the extent of exsolution. a

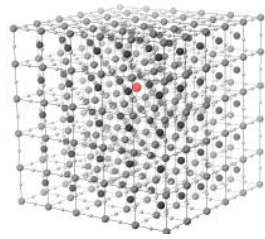

b

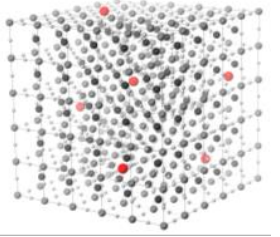

C

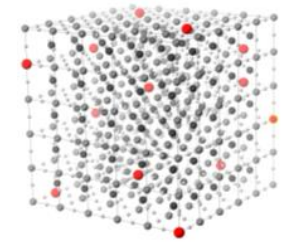

Fig. 1 Illustration of substitution levels in perovskites. An array of $5 \times 5 \times 5$ perovskite unit cells containing various amounts of dopant $M$, $A B_{1-x} M_{x} O_{3}$ : (a) 1 dopant, $x=0.01$.(b) 6 dopants, $x=0.05$ (c) 12 dopants, $\mathrm{x}=0.1$. 
Here we design a series of Rh-substituted A-site deficient perovskite titanates aiming to investigate the possibility of exsolving from dilute amounts of noble metal substituted perovskites. Knowing that exsolution generally occurs from a region limited to a few tens of nanometres under the surface ${ }^{10}$ and in order to increase the extent of exsolution from dilute compositions, we produce perovskite microstructures with smaller grain size than those produced through conventional solid-state synthesis processes. We show that while exsolution is possible, it is still limited to a few nanometres from the surface. In order to better understand how to control the exsolution process, we study the effect of substitution level, reduction time and temperature on the extent of exsolution and the particle size and population. We apply the prepared nanostructures for the $\mathrm{CO}$ oxidation reaction ${ }^{16,17}$, correlating the above-mentioned particle parameters to catalytic reactivity, and demonstrate that in spite of limited exsolution, they still compete well with samples prepared through deposition process that have a higher apparent metal surface loading.

\section{Methods}

\section{Sample preparation}

Perovskite oxide powders were prepared by a modified solid-state synthesis described in detail previously ${ }^{10}$. The synthesis conditions were further modified as explained in the Results section. The as-prepared samples were crushed and sieved to produce powders with particle size between 80$160 \mu \mathrm{m}$. To exsolve particles, the samples were reduced at temperature in a controlled atmosphere furnace, under continuous flow of $5 \% \mathrm{H}_{2} / \mathrm{He}\left(25 \mathrm{~mL} \mathrm{~min}^{-1}\right)$ with heating and cooling rates of $5{ }^{\circ} \mathrm{C} \mathrm{min}-1$. To measure the effect of reduction temperature on the exsolution of $\mathrm{Rh}$ particles, temperatures between $500{ }^{\circ} \mathrm{C}$ and $1000{ }^{\circ} \mathrm{C}$ with a dwell of $10 \mathrm{~h}$ were used. To measure the effect of time at reduction temperature on the exsolution of $\mathrm{Rh}$ particles, samples were reduced at $900{ }^{\circ} \mathrm{C}$ with a dwell of 0,10 or $30 \mathrm{~h}$.

For the preparation of the impregnated sample, $0.6 \%$ $\mathrm{Rh} / \mathrm{Al}_{2} \mathrm{O}_{3}$, a commercial $\gamma-\mathrm{Al}_{2} \mathrm{O}_{3}\left(\sim 100 \mathrm{~m}^{2} \mathrm{~g}^{-1}\right)$ was used as a support. The support was dispersed in a dilute aqueous solution of $\mathrm{Rh}$ nitrate under continuous stirring followed by water evaporation and drying at $90{ }^{\circ} \mathrm{C}$ overnight. The dried material was submitted to calcination $\left(10{ }^{\circ} \mathrm{C} \mathrm{min}^{-1}\right)$, the final temperature being $500{ }^{\circ} \mathrm{C}$ with a dwell of $4 \mathrm{~h}$. After the calcination, the material was sieved to the same size as above, 80-160 $\mu \mathrm{m}$, and reduced under continuous flow of $5 \% \mathrm{H}_{2} / \mathrm{He}$ $\left(25 \mathrm{~mL} \mathrm{~min}^{-1}\right)$ at $550{ }^{\circ} \mathrm{C}$ for $4 \mathrm{~h}$ with heating and cooling rates of $5{ }^{\circ} \mathrm{C} \mathrm{min}^{-1}$.

\section{X-ray diffraction}

The phase purity and crystal structure of the prepared perovskites were confirmed by room temperature XRD by using a PANalytical X'Pert Pro Multipurpose X-ray diffractometer operated in reflection mode.

Rietveld refinement analysis was carried out using GSAS $\|^{18}$.
The following parameters were gradually unlocked and refined: background (shifted Chebyshev polynomial, 3-6 terms), peak shape, unit cell parameters, atomic coordinates, site occupancies, thermal displacement parameters and microstrain. The pseudocubic perovskite cell parameter $a_{p}(\AA ̊)$ was calculated as:

$$
a_{p}=\sqrt[3]{\frac{V}{4}}
$$

Where $V$ is the volume of the perovskite unit cell calculated from Rietveld refinement.

\section{X-ray photoelectron spectroscopy}

X-ray photoelectron spectroscopy (XPS) was carried out at two locations using monochromatic Al X-ray sources using a Thermo Scientific KAlpha photoelectron spectrometer. The data were analysed using CasaXPS software.

\section{Electron microscopy}

High-resolution secondary electron images were obtained using a FEI Helios Nanolab 600 scanning electron microscope (SEM). Transmission Electron Microscopy (TEM) micrographs were obtained on a JEOL JEM-2100 system.

\section{Image analysis}

Particle size distribution and particle population (particles per surface area of perovskite, $\mu \mathrm{m}^{-2}$ ) were calculated based on pixel contrast from SEM micrographs by using a custom made routine in Mathematica, based on a procedure described previously ${ }^{8}$. The particle size distribution and corresponding particle population were integrated to calculate two different values, as follows.

The exsolved Rh atoms per surface area of perovskite $\left(N_{R h}\right)$ represents the total number of $\mathrm{Rh}$ atoms contained within the exsolved particles normalised per surface are of perovskite $\left(\mu \mathrm{m}^{-2}\right)$ :

$$
N_{R h}=\frac{4 \pi \cdot \rho_{R h} \cdot N_{A}}{3 \cdot A_{R h}} \sum_{i} f_{i} \cdot\left(\frac{d_{i}}{2}\right)^{3}
$$

Where $\rho_{R h}, A_{R h}$ are the density and atomic weight of Rh, respectively, $N_{A}$, is Avogadro's constant and $f_{i}$ is the fraction of particles (per area of perovskite, $\mu \mathrm{m}^{-2}$ ) having a diameter $d_{i}$ (nm).

The exsolution depth of $\mathrm{Rh}$ is the depth under the perovskite surface that has been depleted of Rh ions:

$$
D_{R h}=\frac{N_{R h} \cdot a_{p}^{3}}{\zeta}
$$

Where $\zeta$ is the degree of exsolution, mol $\mathrm{Rh}$ per mol of perovskite in $\mathrm{La}_{0.43} \mathrm{Ca}_{0.37} \mathrm{Ti}_{1-x} \mathrm{Rh}_{\mathrm{x}-\zeta} \mathrm{O}_{3}$.

The Rh metal coverage, $\eta_{R h}$, represents the surface area of the exsolved particles (exposed to the gas phase), normalised per surface are of perovskite $\left(\mu \mathrm{m}^{2} \mu \mathrm{m}^{-2}\right)$ :

$$
\eta_{R h}=2 \pi \cdot \sum_{i} f_{i} \cdot\left(\frac{d_{i}}{2}\right)^{2}
$$




\section{Evaluation of catalytic activity}

The catalytic activity of the powders was tested using CO oxidation reaction in a fixed-bed quartz reactor (straight tube with $9 \mathrm{~mm}$ inner diameter) in which $10 \mathrm{mg}$ catalyst was loaded (supported by quartz wool at both sides). All experiments were conducted at atmospheric pressure. A thermocouple (K-type) was placed in proximity to the catalyst bed to measure the sample temperature during the reaction. Another fixed-bed reactor filled by $\mathrm{Al}_{2} \mathrm{O}_{3}$ was placed upstream to this catalyst reactor, which was used to capture some possible carbony species from gas cylinders. The catalytic experiments were conducted at flow rates of $3 \times 10^{-4} \mathrm{~mol} \mathrm{~s}^{-1}$ (gas hourly space velocity, i.e the volumetric flow rate of the reacting gases divided by the fixed bed volume (GHSV) $=26000 \mathrm{~h}^{-1}$, volumetric flow rates are given at normal temperature and pressure (NTP) correspond to $450 \mathrm{~cm}^{3} \mathrm{~min}^{-1}$ ). The flow rates were controlled by electronic mass flow controllers and also measured at the outlet using a Varian digital flow meter (1000 series). To study the effect of temperature, the materials were heated in an inlet gas mixture of $1 \%$ of $\mathrm{O}_{2}$ and $0.6 \%$ of $\mathrm{CO}$ from $100{ }^{\circ} \mathrm{C}$ up to 500 ${ }^{\circ} \mathrm{C}$. The temperature was held during heating after each step of $20^{\circ} \mathrm{C}$, the holding time being varied depending on the time the reaction rate needed to become steady: i.e., the rate of $\mathrm{CO}_{2}$ production did not vary by more than $\pm 5 \%$ over $60 \mathrm{~min}$. An XTREAM- $\mathrm{CO}_{2}$ analyzer provided by Rosemount was used to analyze the carbon dioxide $\left(\mathrm{CO}_{2}\right)$ mole fraction in the product stream. The minimum detectable $\mathrm{CO}_{2}$ mole fraction for the XTREAM-CO2 analyzer was $1 \mathrm{ppm}$ which corresponds to a minimum measurable rate of $\mathrm{CO}_{2}$ production of $3 \times 10^{-10} \mathrm{~mol}$ $\mathrm{s}^{-1}$ with typical flow rate at $3 \times 10^{-4} \mathrm{~mol} \mathrm{~s}^{-1}\left(450 \mathrm{~cm}^{3} \mathrm{~min}^{-1}\right)$. The steady $\mathrm{CO}_{2}$ mole fraction was used to calculate conversion of $\mathrm{CO}$ at the temperature of measurement.

\section{Results and discussion}

\section{Towards dilute substitution of $\mathrm{Rh}$ in perovskite titanate}

In order to ensure strict control of stoichiometry (important due to the presence of A-site vacancies and low substitution levels) it is important to use a solid-state synthesis preparation method. However, this usually requires high reaction temperatures $\left(>1200^{\circ} \mathrm{C}\right)$ and yields large grains $(>10 \mu \mathrm{m})$. In turn, this makes it difficult to incorporate $\mathrm{Rh}_{2} \mathrm{O}_{3}$ into the perovskite (the oxide decomposes to Rh metal at $\sim 1150{ }^{\circ} \mathrm{C}^{19}$ ), while the large grains would limit ion diffusion to the surface and therefore exsolution. In order to overcome the above limitations and lower phase formation temperature to $1100{ }^{\circ} \mathrm{C}$, we use a Ca-based titanate since $\mathrm{Ca}$ promotes lowertemperature phase formation and ion diffusion ${ }^{20}$. We introduce a high degree of A-site vacancies to further promote ion diffusion and also subsequently exolution, thus employing the series of $\mathrm{La}_{0.43} \mathrm{Ca}_{0.37} \mathrm{Rh}_{\mathrm{x}} \mathrm{Ti}_{1-\mathrm{x}} \mathrm{O}_{3}$.We synthesised the series members with $\mathrm{x}=0,0.01,0.03$ and 0.06 (henceforth are referred to as Rh0, Rh1, Rh3 and Rh6, respectively). As observed by XRD (Fig. 2a), these perovskites are single phase. Microstructural analysis by SEM (Fig. 2b) reveals the successful preparation of a perovskite with grains of $500 \mathrm{~nm}$ in size, significantly lower than those achieved for typical solid-state prepared perovskites. The XRD data was further analysed by Rietveld refinement (Fig. 2c) in order to extract crystallographic information for the newly prepared perovskite phases. This analysis revealed that all the perovskites share the same orthorhombic $1 \mathrm{bmm}$ crystal structure although, as expected, they display different unit cell parameters (Fig. 2c). To facilitate comparison of the unit cell parameters as a function of substitution level, their corresponding pseudocubic cell parameters were calculated by using Eq. 1 and their respective unit cell volumes derived from Rietveld refinement; a plot of this is shown in Fig. 2e. This plot reveals that there is a linear, increasing correlation between the Rh0, Rh3 and Rh 6 members of the series indicating that in these samples Rh substituted in an oxidation state lower than the host ion $\left(\mathrm{Ti}^{4+}\right)$ and thus probably in a state of about $+3 /+4$. For Rh1, there is a drop in the cell parameter as compared to the rest of the series, indicating that Rh substitutes as a smaller, higher oxidation state ion, probably closer to +4 (Fig. 2c). This is probably an indication of stronger lattice interaction in more dilute concentrations which forces $\mathrm{Rh}$ in a closer oxidation state to that of the host lattice ion Ti which is also +4 . These conclusions are also supported by evidence of these oxidation states at the surface of the materials, as measured by X-ray photoelectron spectroscopy (XPS). These results, summarised in Fig. $2 f$, indicate that upon increasing $\mathrm{Rh}$ substitution level, the core level spectra of $\mathrm{La}, \mathrm{Ca}, \mathrm{Ti}$ and $\mathrm{O}$ are largely unaffected, i.e. their oxidation state and coordination environment do not change, but there are subtle changes in the oxidation state of $\mathrm{Rh}$. The core level spectra indicate the presence of a peak at $307.7 \mathrm{eV}$ which can be assigned to $\mathrm{Rh}^{3+}$ in $\mathrm{Rh}_{2} \mathrm{O}_{3}$ environment ${ }^{21}$. This peak is only present for Rh3 and Rh6 samples and missing in the Rh1 sample. The peak at $309.5 \mathrm{eV}$ has been assigned to both $\mathrm{Rh}^{3+}$ and $\mathrm{Rh}^{4+}$ in the literature ${ }^{22}$ depending on the coordination environment of $\mathrm{Rh}$ and thus cannot unequivocally distinguished based on core spectra alone. To clarify this aspect, we investigate the valence band spectra to reveal the electron count in the $d$ band of these perovskites. This measurement indeed showed that Rh can only be found in the +4 state in the Rh1 sample, while Rh3 and Rh6 both have a considerable fraction of +3 state (up to $50 \%$ based on literature data) ${ }^{23}$.

Overall, the results presented above demonstrate we have successfully prepared highly porous, single phase $\mathrm{Rh}$-containing perovskites and that at dilute substitution levels $\mathrm{Rh}$ ions interact more strongly with the lattice, which accounts in part for the difficulty in exsolving from such dilute compositions.

\section{Effect of substitution level on Rh exsolution}

Figure $3 a$ shows the microstructure of materials with different substitution levels after reduction at $900{ }^{\circ} \mathrm{C}$ for $10 \mathrm{~h}$, typical for exsolving from a titanate lattice ${ }^{24}$.

With increasing substitution level, the particle size decreases and the particle population increases (Fig 3c-d). These trends can be explained in the context of particle nucleation and growth theory and considering the availability of exsolvable ions for each system. For example, in order to create one unit cell of Rh metal (1 nm metal cluster, Fig 3f) from Rh1, Rh3 and Rh6 it is required to exsolve from 1400, 480 and 280 perovskite unit cells, or, equivalently from a perovskite region of 4, 1.3, $0.9 \mathrm{~nm}$ radius, respectively (Fig $3 \mathrm{e}$ ). This means that in the dilute system, ions would have to travel considerably longer distances to even form a nucleation cluster, and would therefore preferentially grow existing nuclei, accounting for lower particle population and larger size. For the higher concentration systems, there is an increased likelihood of nucleation due to very close proximity of exsolvable ions in the lattice which 
a

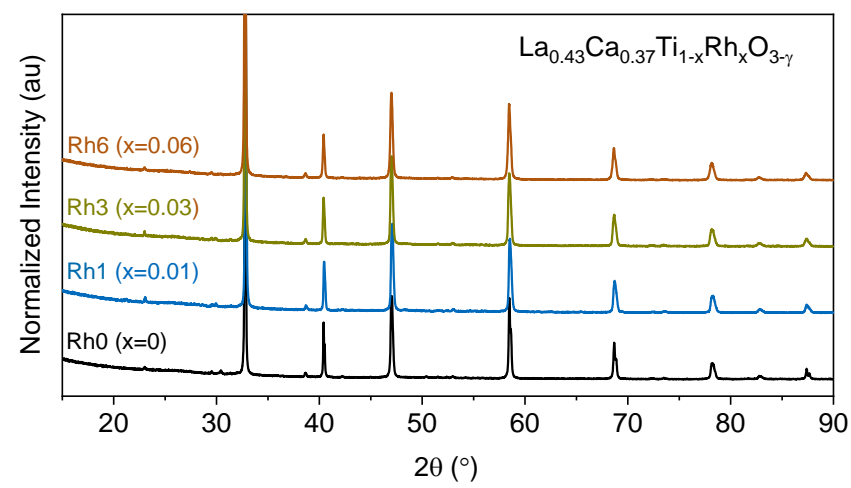

b
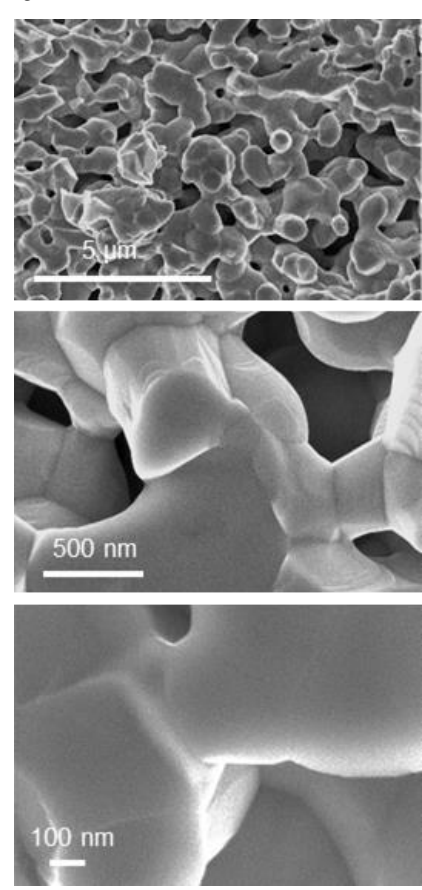

d

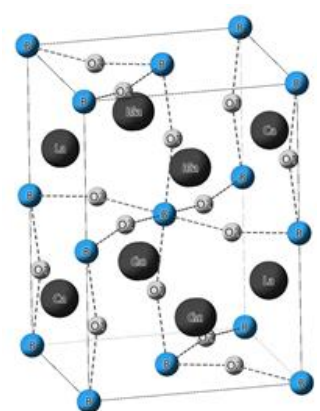

e

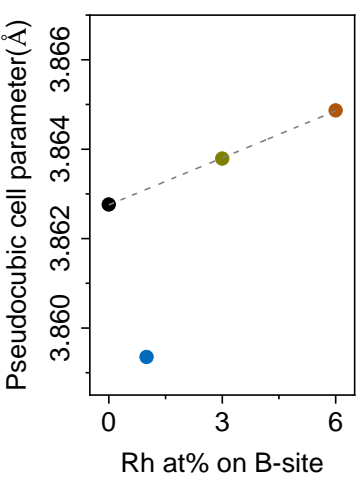

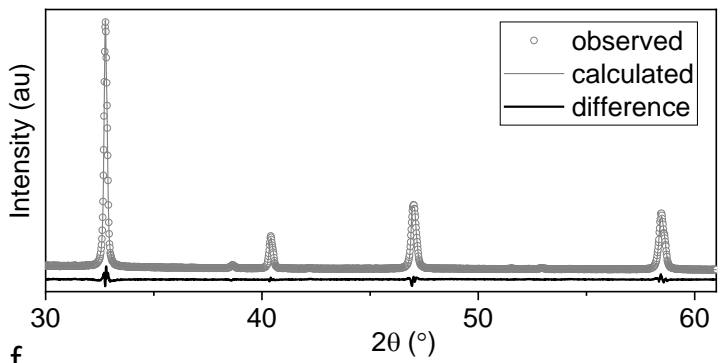

$\mathrm{f}$
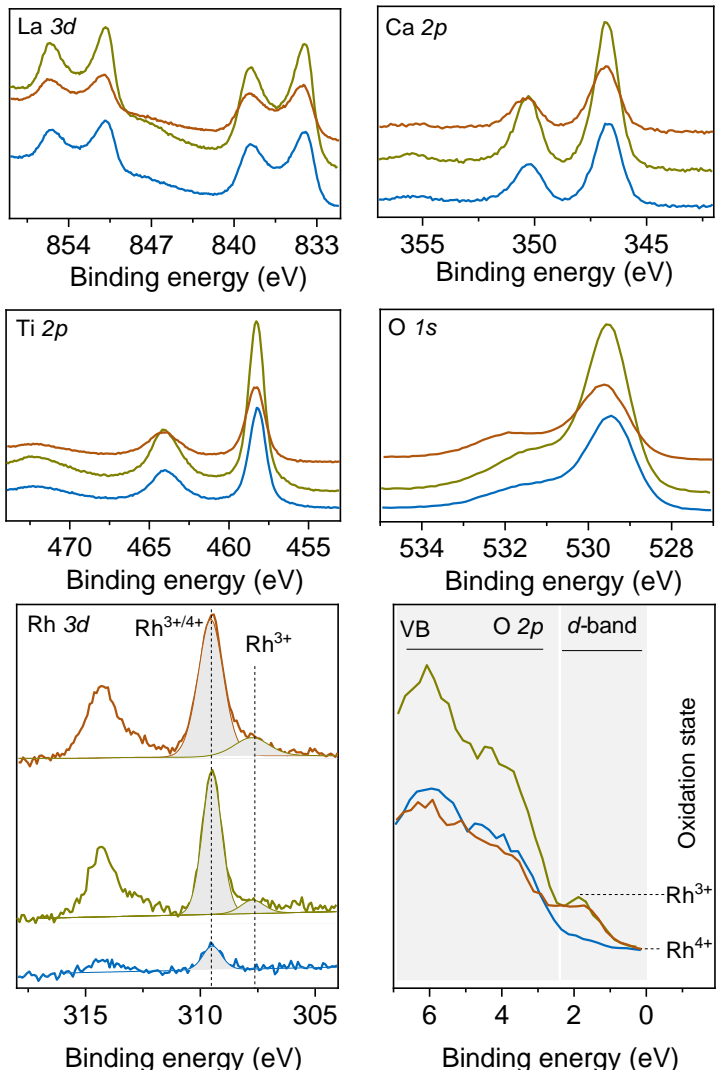

Fig. 2 Towards dilute substitution of Rh into perovskite titanate. (a) Room temperature XRD patterns of $\mathrm{La}_{0.43} \mathrm{Ca}_{0.37} \mathrm{Rh}_{\mathrm{x}} \mathrm{Ti}_{1-\mathrm{x}} \mathrm{O}_{3^{\prime}}$, for different substitution levels. All diffractograms are normalised on a scale from 0 to 1. (b) SEM micrographs showing the microstructure of the asprepared $\mathrm{La}_{0.43} \mathrm{Ca}_{0.37} \mathrm{Rh}_{\mathrm{x}} \mathrm{Ti}_{1-\mathrm{x}} \mathrm{O}_{3}$ system, at different magnifications highlighting that the average perovskite grain size is $500 \mathrm{~nm}$. (c) Rietveld refinement analysis corresponding to a fresh sample shown in (a) (Space group $\mathrm{lbmm}, w R=8 \%$ ). Individual cell parameters are: $\mathrm{RhO}(\mathrm{a}=$ $\left.5.4654 \AA, b=5.4665 \AA, c=7.7164 \AA, V=230.54 \AA^{3}\right), R h 1\left(a=5.4641 \AA, b=5.4603 \AA, c=7.7065 \AA, V=229.93 \AA^{3}\right), R h 3(a=5.4655 \AA, b=$ $\left.5.4705 \AA, c=7.7167 \AA, V=230.72 \AA^{3}\right), \operatorname{Rh} 6\left(a=5.4762 \AA, b=5.4660 \AA, c=7.7211 \AA, V=231.12 \AA^{3}\right)$. (d) Crystal structure illustration obtained from the Rietveld analysis shown in (b). (e) Pseudocubic unit cell parameter as a function of Rh substitution, $x$, derived from the Rietveld refinement of the XRD patterns shown in (a). (f) Core level and valence band (VB) XPS spectra of selected samples from (a).

favours higher particle populations, as opposed to growing particle size. These observations seem to be confirmed by the apparent correlation between particle size and required concentration of ions for nucleation, which levels off after Rh3 (compare Fig. $3 c$ to $3 e)^{25}$.

Particle size distributions follow a near-gaussian shape, while the distribution of particle size becomes narrower with higher substitution levels (Fig. 3b). This is also probably due to the differences in availability of exsolvable ions which, for higher concentration would enable more homogeneous nucleation. We choose to further investigate the exsolution of $\mathrm{Rh}$ in the most dilute composition, $\mathrm{La}_{0.43} \mathrm{Ca}_{0.37} \mathrm{Rh}_{0.01} \mathrm{Ti}_{0.99} \mathrm{O}_{3}$, because, despite the fact that it is more challenging, this will result in the most efficient use of noble metals.

\section{Effect of reduction time on $\mathrm{Rh}$ exsolution}

In order to identify the effect of the reduction duration on the exsolution of $\mathrm{Rh}$ we reduce the $\mathrm{La}_{0.43} \mathrm{Ca}_{0.37} \mathrm{Rh}_{0.01} \mathrm{Ti}_{0.99} \mathrm{O}_{3}$ at $900{ }^{\circ} \mathrm{C}$ with the dwell times being 0,10 and $30 \mathrm{~h}$ (Fig. 4a). It seems that in isothermal conditions, prolonged dwell has no major effects on the particle size (Fig. 4b), which varies between 4.5 to about $3.5 \mathrm{~nm}$. On the contrary, with increasing dwell time the population of the particles increases almost 3 times (Fig. 4c). This would indicate that longer reduction times favour the 
a

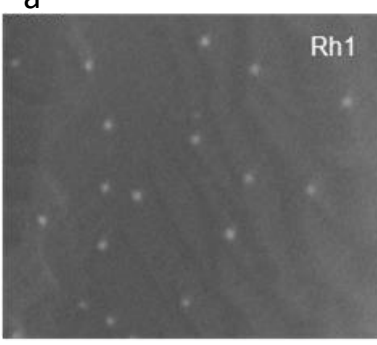

b

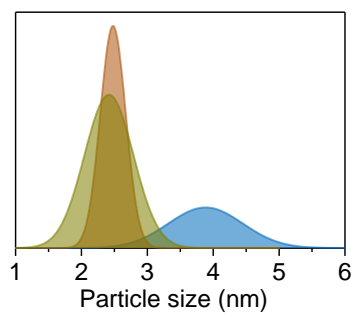

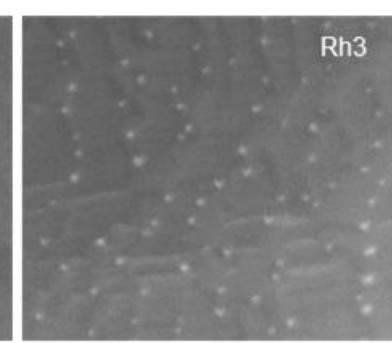

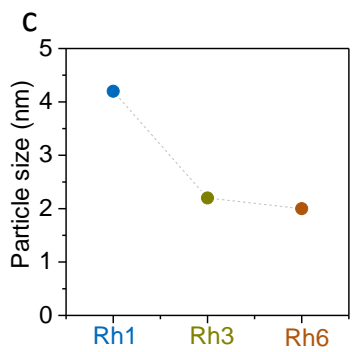

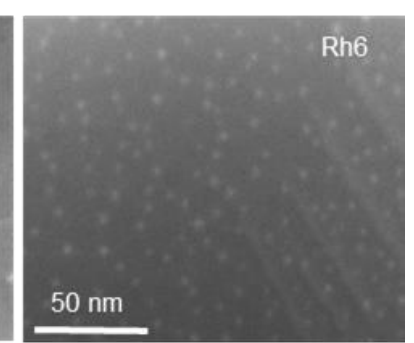

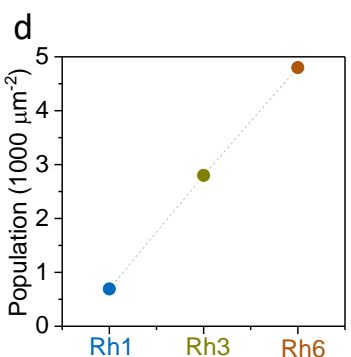

$f$

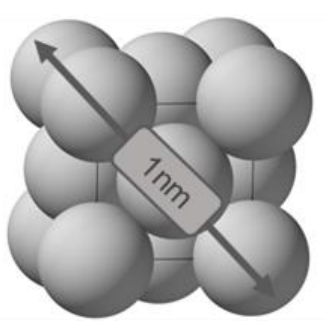

e

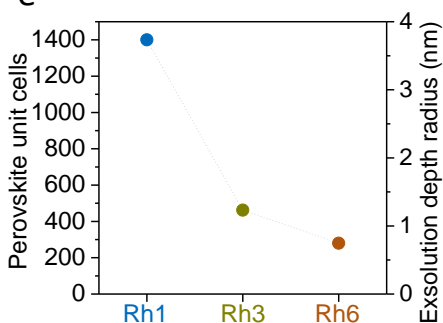

Fig. 3 Effect of Rh doping on exsolution. (a) SEM images showing details of surface particles after reduction at $900{ }^{\circ} \mathrm{C}$. (b) Particle size distribution. (c) Average particle size. (d) Population density for $\mathrm{La}_{0.43} \mathrm{Ca}_{0.37} \mathrm{Rh}_{\mathrm{x}} \mathrm{Ti}_{1-\mathrm{x}} \mathrm{O}_{3}$ with $\mathrm{x}=0.01,0.03$ and 0.06 . (e) Required perovskite unit cells and exsolution depth radius for exsolution for the nucleation of $1 \mathrm{~nm}$ Rh cluster from $\mathrm{La}_{0.43} \mathrm{Ca}_{0.37} \mathrm{Rh}_{\mathrm{x}} \mathrm{Ti}_{1-\mathrm{x}} \mathrm{O}_{3}$ with $\mathrm{x}=0.01,0.03$ and 0.06 . (f) Illustration of $1 \mathrm{~nm}$ Rh cluster.

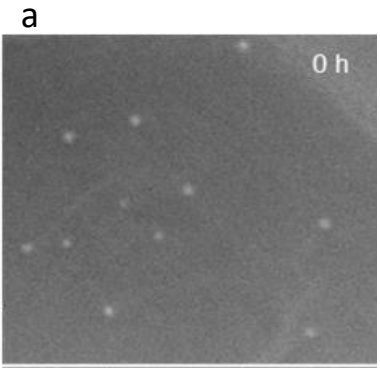

$10 \mathrm{~h}$

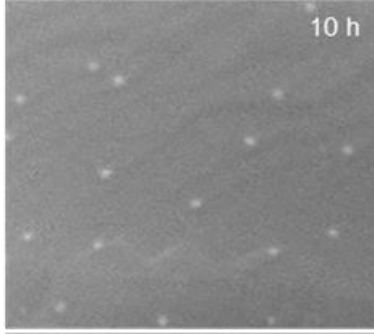

$30 \mathrm{~h}$

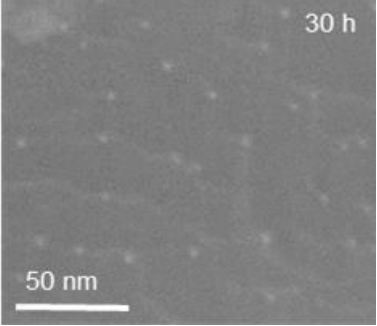

b
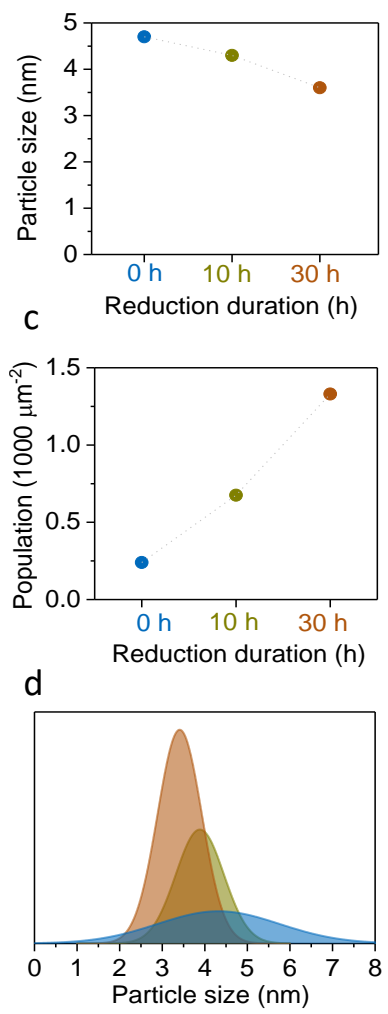

Fig. 4 Effect of reduction time on $\mathrm{Rh}$ exsolution for $\mathrm{La}_{0.43} \mathrm{Ca}_{0.37} \mathrm{Rh}_{0.01} \mathrm{Ti}_{0.99} \mathrm{O}_{3 .}$ (a) SEM images showing details of surface particles. (b) Average particle size. (c) Population density. (d) Particle size distribution after reduction at $900{ }^{\circ} \mathrm{C}$ for $0 \mathrm{~h}, 10 \mathrm{~h}$ and $30 \mathrm{~h}$.

formation of additional small particles through the diffusion of $\mathrm{Rh}$ ions to the surface from deeper within the perovskite lattice. Examination of the particle size distribution reveals that the samples reduced for longer durations have more uniform

particle size in comparison to the shorter reductions where particle size distribution is wider (Fig. 4d). These facts combined provide mechanistic insight into the formation of the particles during exsolution. As opposed to samples prepared by deposition method where over time agglomeration occurs, here more particles nucleate.

\section{Effect of reduction temperature on Rh exsolution}

Reduction temperature should have a considerable effect on the extent of exsolution because diffusion of species is strongly affected by temperature. In order to investigate its effect, we reduce the $\mathrm{Rh} 1$ titanate in the $500-1000{ }^{\circ} \mathrm{C}$ temperature range (Fig 5a). At lower temperatures $\left(500-700{ }^{\circ} \mathrm{C}\right)$, the particle size remains almost constant at $2 \mathrm{~nm}$ while population doubles when the temperature increases from 500 to $700{ }^{\circ} \mathrm{C}$. This is probably due to the fact that at $500{ }^{\circ} \mathrm{C}$ the reducibility of the $\mathrm{Rh}$ ions is still relatively low and not a sufficient number can exsolve. Normally $\mathrm{Rh}$ in oxide form would reduce at $300^{\circ} \mathrm{C}$, but being incorporated into the titanate lattice which has much lower reducibility, means that its reduction temperature shifts to higher values ${ }^{26}$, requiring higher reduction temperature to be converted to metal. In the temperature range between 700 and $1000^{\circ} \mathrm{C}$, the particle size gradually increases from 2 to $5 \mathrm{~nm}$, while the population density decreases from $\sim 2500 \mu \mathrm{m}^{-2}$ to about $500 \mu^{-2}$ (Fig5. b-c). These results are consistent with nucleation/growth theory which suggests that at low temperature nucleation is favoured, while at high temperatures growth ${ }^{15,27}$. As reduction temperature increases, we observe a much broader distribution of particle size (Fig. 5d). As illustrated by Fig. 4 , nucleation largely seems to occur during the heating stage, which implies that as the reduction temperature increases so does the time window for nucleation of particles, which would occur at increasingly higher temperatures. Consequently, particles nucleated after heatingto $1000^{\circ} \mathrm{C}$ would display a wider range of sizes as compared to their lower temperature reduced counterparts. Additionally, dwelling at 
a

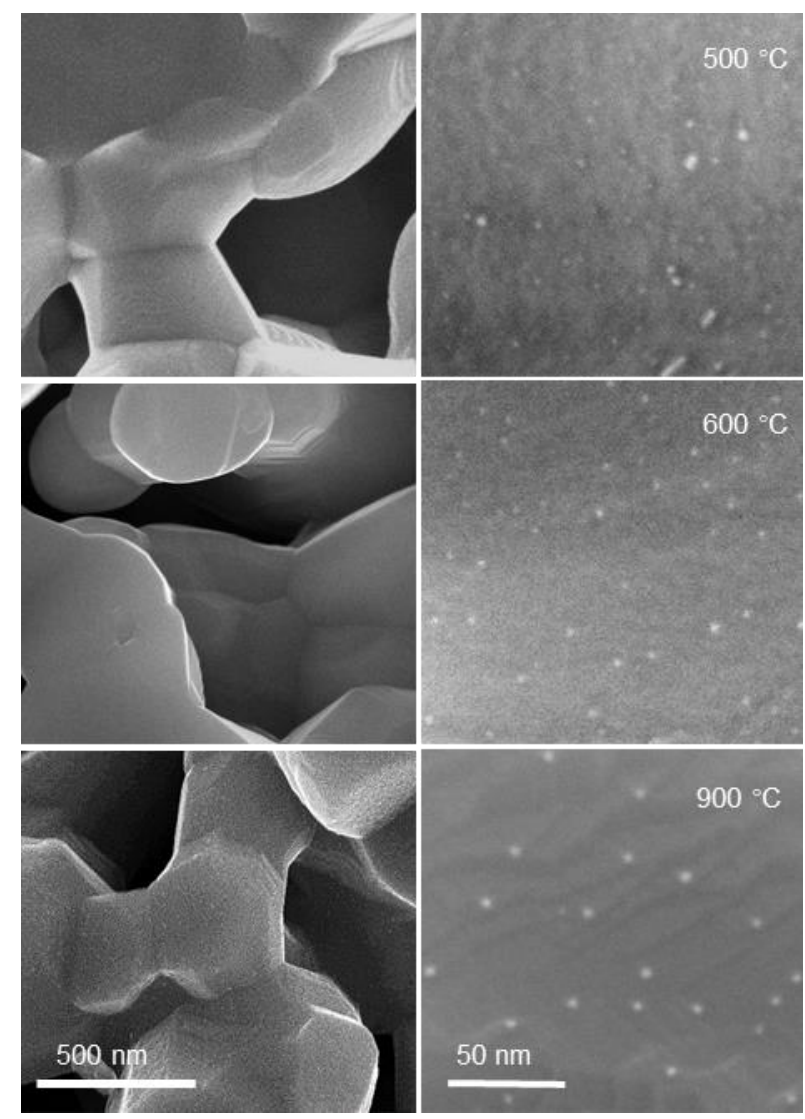

b

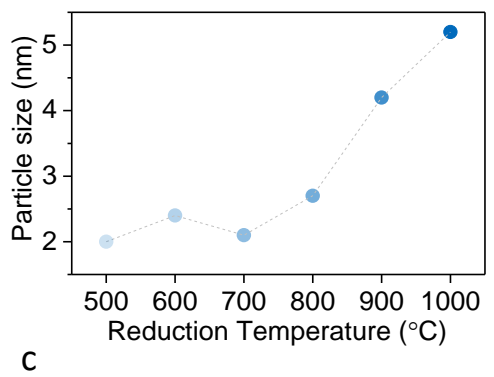

C

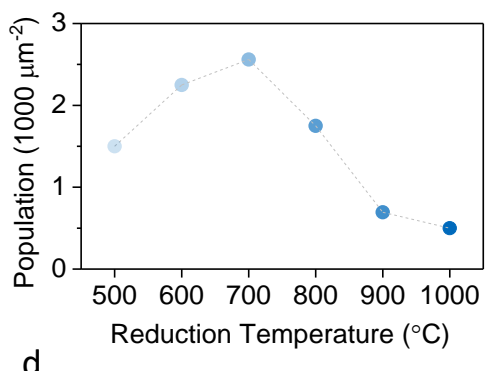

d

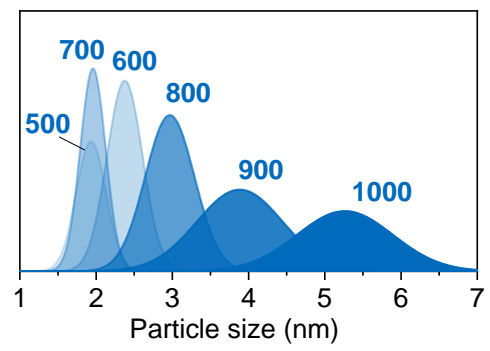

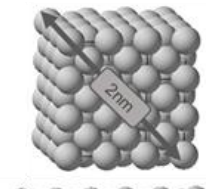
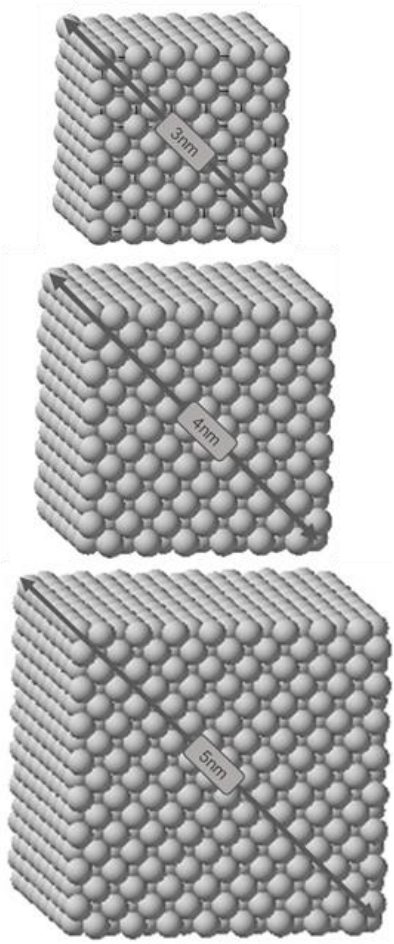

Fig. 5 Effect of reduction temperature on $\mathrm{Rh}$ exsolution for $\mathrm{La}_{0.43} \mathrm{Ca}_{0.37} \mathrm{Rh}_{0.01} \mathrm{Ti}_{0.99} \mathrm{O}_{3}$. (a) $\mathrm{SEM}$ images, lower magnification and details, of surface particles. (b) Average particle size. (c) Population density. (d) Particle size distribution after reduction at $500{ }^{\circ} \mathrm{C}, 600^{\circ} \mathrm{C}, 700^{\circ} \mathrm{C}$ $800^{\circ} \mathrm{C}, 900^{\circ} \mathrm{C}$ and $1000^{\circ} \mathrm{C}$ for $10 \mathrm{~h}$. (e) Illustration of $2,3,4,5 \mathrm{~nm}$ Rh clusters corresponding to average particle sizes presented in (b).

temperature not only adds newly exsolved atoms to the particles, formed during heat up, but also nucleates additional particles.

\section{Extent of exsolution as a function of doping, reduction time and temperature}

The data shown above illustrate different combinations of particle size and population that can be achieved by controlling various factors. By combining the particle size and population according to Eq. 2, the amount of exsolved Rh metal per surface area of perovskite $\left(\mathrm{N}_{\mathrm{Rh}}\right)$ can be calculated for each individual case, as shown in Fig. 6 . In turn, this allows one to estimate the average depth from which exolution has occurred, $D_{\mathrm{Rh}}$ (Eq. 3), and the degree of exolution from that region $(\zeta, \mathrm{mol} \mathrm{Rh}$ per mol of perovskite, $\left.\mathrm{La}_{0.43} \mathrm{Ca}_{0.37} \mathrm{Rh}_{\mathrm{x}-\zeta} \mathrm{Ti}_{1-\mathrm{x}} \mathrm{O}_{3}\right)$ and thus understand the efficiency of the exsolution process. Fig. 6a shows that as the Rh substitution increases, Rh1 and Rh3 show similar amount of exsolved metal $N_{R h}\left(\sim 2 \times 10^{6} \mu \mathrm{m}^{-2}\right)$, but roughly two fold lower than those shown by Rh6. This suggests that the amount of exsolved metal is not necessarily proportional to the substitution level and indeed, between Rh1 and Rh3, employing Rh1 would actually make more efficient use of the noble metal, as suggested above.

Figure $6 \mathrm{~b}$ reveals that the amount of exsolved metal $\mathrm{N}_{\mathrm{Rh}}$, that forms during heat-up of the sample (no dwell at temperature) is actually quite high $\left(\sim 10^{6} \mu \mathrm{m}^{-2}\right)$ and this increases twofold after
$10 \mathrm{~h}$ dwell after which it plateaus, suggesting that a large fraction of the metal exsolves in the early stages of the reduction process. Figure $6 c$ shows that the amount of exsolved metal $\mathrm{N}_{\mathrm{Rh}}$ varies across about one order of magnitude when the reduction temperature varies from 500 to $1000{ }^{\circ} \mathrm{C}$. Nonetheless, as Fig. $6 \mathrm{~d}$ reveals, the maximum depth from which $\mathrm{Rh}$ was exsolved across all the cases discussed above is of up to $10 \mathrm{~nm}$. This plot also suggests that there are two approaches for maximizing the exsolution of $\mathrm{Rh}$; decreasing the particle size of the perovskite $<20-50 \mathrm{~nm}$, thus exsolving from a larger fraction of the bulk and having more surface area to exsolve from, or increasing the degree of exsolution from the lattice, for example by changing the stoichiometry of the material to make the lattice more mobile and easier to exsolve from ${ }^{28}$.

\section{Catalytic activity in $\mathrm{CO}$ oxidation}

In order to understand the effect of the particle size and population of Rh clusters on catalytic activity, we tested the samples in $\mathrm{CO}$ oxidation. The catalytic tests were carried out under oxidizing feed conditions $\left(0.6 \% \mathrm{CO}, 1 \% \mathrm{O}_{2}\right)$, as a function of temperature (up to $500^{\circ} \mathrm{C}$ ), in a so-called "light-off" experiment. The minimum temperature for any measurable $\mathrm{CO}_{2}$ detection was around $200{ }^{\circ} \mathrm{C}$ for all exsolved samples except the one reduced at $500^{\circ} \mathrm{C}$ which was higher $\left(270^{\circ} \mathrm{C}\right)$.

We compare the samples in terms of the temperature at which they achieve 5\% and 50\% CO conversion (henceforth 
a

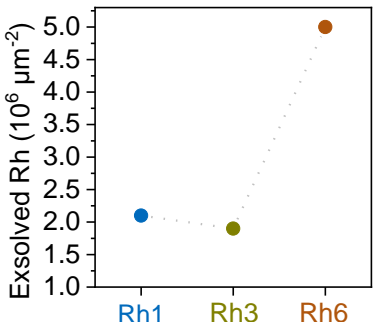

C

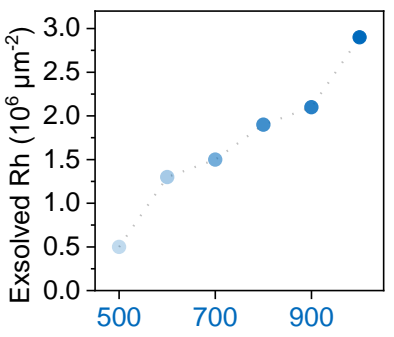

Reduction temperature $\left({ }^{\circ} \mathrm{C}\right)$ b

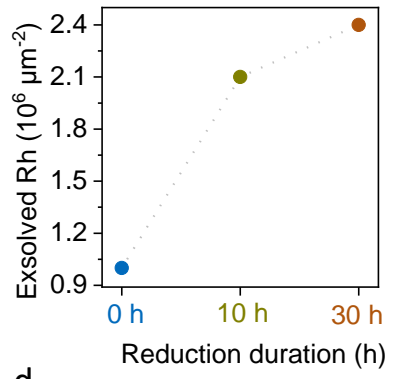

d

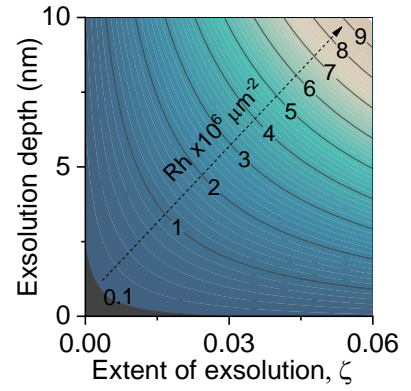

Fig. 6 Exsolution as a function of doping, reduction time, reduction temperature. Amount of exsolved $\mathrm{Rh}$ metal atoms per surface area of perovskite $\left(\mathrm{N}_{\mathrm{Rh}}\right)$ as a function of: (a) Rh substitution level, (b) reduction time at $900^{\circ} \mathrm{C}$, (c) reduction temperature. (d) $2 \mathrm{D}$ plot of $\mathrm{N}_{\mathrm{Rh}}$ as a function of the exsolution depth and the degree of exolution $\zeta$ in $\left.\mathrm{La}_{0.43} \mathrm{Ca}_{0.37} \mathrm{Rh}_{\mathrm{x}-\zeta} \mathrm{Ti}_{1-\mathrm{x}} \mathrm{O}_{3}\right)$.

referred to as $T_{5}$ and $T_{50}$, respectively) and also in terms of their kinetic behaviour below $\mathrm{T}_{5}$. (Fig. 7).

To investigate the contribution of the support towards the catalytic activity, a sample that was not substituted (Rh0) and

one that was substituted but not exsolved were also tested under the same conditions for reference. The former showed no measurable activity while the latter demonstrated only $5 \%$ conversion at around $500{ }^{\circ} \mathrm{C}$. This indicates that the perovskite largely has a support function and the activity is primarily due to the $\mathrm{Rh}$ particles. Examination of the plot of the light-off curves revealed that the Rh1 exsolved samples form three distinct groups of reactivity (Fig. 7a). The sample reduced at 500 ${ }^{\circ} \mathrm{C}$ displays the lowest activity, with a $\mathrm{T}_{50}$ value of about $375^{\circ} \mathrm{C}$. The second zone of activity corresponds to the medium temperature reduced samples $\left(T_{R}=600-700{ }^{\circ} \mathrm{C}\right)$ which, as compared to the previous sample, display a $T_{50}$ value decreased by almost $100{ }^{\circ} \mathrm{C}$. Finally, the high temperature reduced samples $\left(T_{R}=800-1000{ }^{\circ} \mathrm{C}\right)$ are more active, reaching $T_{50}$ values of about $250{ }^{\circ} \mathrm{C}$. For all the above samples, $\mathrm{T}_{5}$ varies in a similar manner but within a narrower temperature range, between 220 and $275^{\circ} \mathrm{C}$.

Interestingly, the temperature window between $T_{5}$ and $T_{50}$ is different for these three zones of activity. This temperature window is of about 100,50 and $30^{\circ} \mathrm{C}$ for the low, medium and high temperature reduced samples, respectively. Generally, for noble metal catalysts this temperature window is narrower than what is observed here implying that the interaction of the exsolved metal particles with the support might play a very important role in these samples. Evidence of particle-substrate interactions can be seen in the activation energies of the samples as measured in the lower temperature range of activity. The activation energies range from 100 to $157 \mathrm{~kJ} \mathrm{~mol}^{-1}$ (Fig 7b) which are characteristic of activation energy values seen when supports with relatively low reducibility are employed ${ }^{29}$. Indeed, the supports should have low reducibility since they have already been extensively reduced during the reduction treatment required to exsolve particles. Therefore, the higher the reduction temperature, the lower the reducibility of the
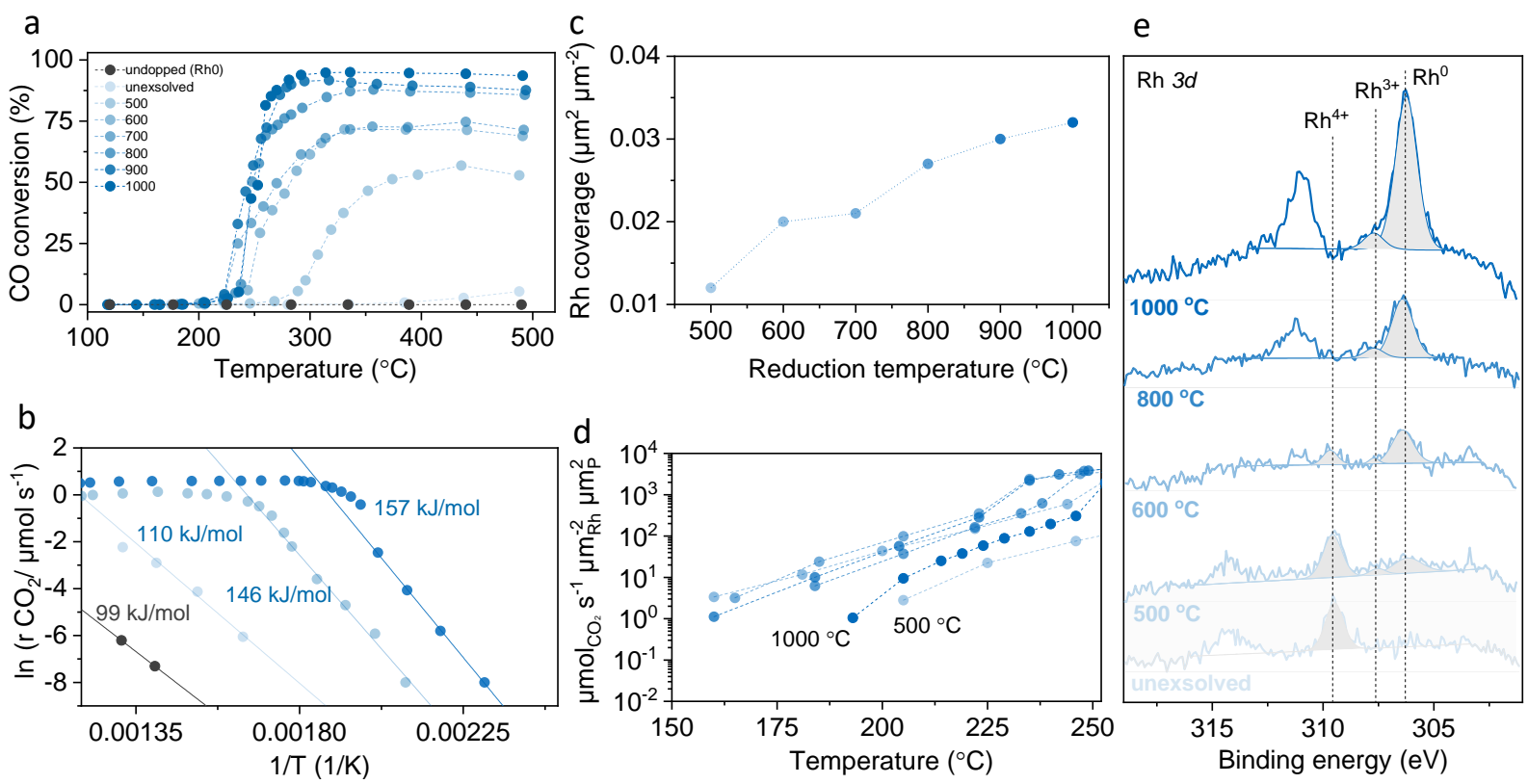

Fig. 7 Catalytic activity of $\mathrm{La}_{0.43} \mathrm{Ca}_{0.37} \mathrm{Rh}_{0.01} \mathrm{Ti}_{0.99} \mathrm{O}_{3-\delta}$ reduced at different temperatures applied for CO oxidation. (a) CO conversion as a function of temperature. (b) Arrhenius plots and activation energies calculated for (a). (c) Rh coverage as a function of reduction temperature. (d) Rates of $\mathrm{CO}_{2}$ production divided by Rh metal coverage $\eta_{\mathrm{Rh}}$ with temperature for the samples listed in (a). (e) Core level XPS spectra of Rh for selected samples shown in (a). 
perovskite, which in turn increases activation energy, as observed in Fig $7 \mathrm{~b}$. The unexsolved sample (no Rh nanoparticles present on the surface of the support), which has not been reduced prior to testing, shows the lowest activation energy close to the values reported for similar perovskite oxides ${ }^{30-32}$.

The relation between activity and particle characteristics seems to be counter-intuitive because the lower temperature reduced samples have the highest population and lowest particle size (typically beneficial for catalytic processes), yet also the lowest activity. (compare Fig. 5b,c and Fig. 7a). However, when the particle size and population are factored together, through the metal coverage $\eta_{R h}$ (Eq. 4, results in Fig. 7c), it becomes apparent that the increase in conversion and catalytic rates (Fig. 7a,b) increases with increasing metal coverage. This is not surprising considering that the active sites for the $\mathrm{CO}$ oxidation reaction are likely located on the metal particles, as reported previously in the literature ${ }^{33}$ and as seen above for the unsubstituted support. Inspection of Fig. 7a in comparison to Fig. 7c reveals that indeed the Rh coverage correlates with the observed activity trend across samples, even though not in a directly proportional manner suggesting that other effects might come into play, including particle size and oxidation state effects as disused below. This is more obvious when the catalytic rates are normalised with respect to the $\mathrm{Rh}$ metal coverage $\eta_{R h}$, as shown in Fig. $7 \mathrm{~d}$. This figure shows that when the activity is normalised in such a way, most of the samples exhibit similar reactivity across the selected temperature range, except the samples reduced at the lowest and highest temperatures, possibly indicating a different state of the $\mathrm{Rh}$ particles for these two samples.

To investigate the effect of oxidation state on activity we carry out XPS analysis on selected samples (unexsolved, reduced at $500,600,800$ and $1000{ }^{\circ} \mathrm{C}$ ), as shown in Fig. 7e. The core level $\mathrm{Rh}$ spectra indicates the presence of $\mathrm{Rh}^{4+}(309.5 \mathrm{eV}$, see discussion in the first results section), $\mathrm{Rh}^{3+}$ (in $\mathrm{Rh}_{2} \mathrm{O}_{3}$ form, $307.7 \mathrm{eV})$ and $\mathrm{Rh}^{0}(306.5 \mathrm{eV})^{21,22}$. As discussed above, the unexsolved sample contains Rh only in +4 state. Upon reduction at $500{ }^{\circ} \mathrm{C}$ a small amount of $\mathrm{Rh}^{0}$ is formed together with a similar amount of $\mathrm{Rh}^{3+}$ ( $\mathrm{Rh}_{2} \mathrm{O}_{3}$ form). However, the overall state of the surface is very similar to the unexsolved sample possibly accounting for the relatively lower reactivity of this sample (Fig. $7 \mathrm{a}, \mathrm{d})$. As the reduction temperature is increased to 600,800 and $1000{ }^{\circ} \mathrm{C}$, the +4 state is gradually converted to $\mathrm{Rh}^{0}$, with some additional $\mathrm{Rh}^{3+}\left(\mathrm{Rh}_{2} \mathrm{O}_{3}\right)$ forming. The $\mathrm{Rh}_{2} \mathrm{O}_{3}$ likely corresponds to the surface oxide layer covering the metallic nanoparticles which formed as a result of exposing the samples to atmospheric conditions after the reduction treatment. Overall, the increase in $\mathrm{Rh}$ metal content at the surface with increasing reduction temperature is consistent with the observed increase in activity in this series (Fig. 7a). However, as the reduction temperature increases, the metal particle size also increases, possibly accounting for the lower activity to coverage ratio observed for the sample reduced at $1000^{\circ} \mathrm{C}$ as compared to the rest of the series (Fig. 7d). It has been suggested that the activity of Rh catalysts depends on its oxidation state which in turn depends on their particle size. Rh particles smaller than $2 \mathrm{~nm}$ are usually prone to oxidize and remain in an oxidized state, while particles larger than $4 \mathrm{~nm}$ have the ability to stay reduced ${ }^{29}$.

Generally, the detailed relation between oxidation state and reactivity is not clear at present. Some of the previously published studies claim that metallic Rh is active while oxidized
$\mathrm{Rh}$ is a spectator species ${ }^{34}$, others that both metallic $\mathrm{Rh}$ and underlying supports including $\mathrm{Rh}^{3+}$ ions are active and others that a thin surface trilayer of O-Rh-O can be active for this process but further surface oxidation could result in the deactivation of the catalyst ${ }^{35,36}$. A combination of the above findings could explain our catalytic results, although the general trend of activity seems to be dictated by the Rh coverage $\eta_{R h}$.

\section{Exsolution vs infiltration}

In order to exemplify the applicability of dilute Rh metal exsolution for the $\mathrm{CO}$ oxidation reaction, we compare a selected material (reduced at $900{ }^{\circ} \mathrm{C}, \mathrm{Rh}-\mathrm{eABO}_{3}$ ) to an a $\mathrm{Rh}$ impregnated $\gamma$-alumina ( $\mathrm{Rh}-\mathrm{iAl}_{2} \mathrm{O}_{3}$ ) which is one of the most commonly used materials for automotive exhaust applications. This material was impregnated with the same nominal amount of Rh metal (0.6 wt.\%), corresponding to $\mathrm{Rh} 1, \quad \mathrm{La}_{0.43} \mathrm{Ca}_{0.37} \mathrm{Ti}_{0.99} \mathrm{Rh}_{0.01} \mathrm{O}_{3}$ perovskite.

Examination of the structure of these catalysts shown in Fig. $8 a-c$ indicates that the surface area of the perovskite samples is much lower than that of the $\gamma$-alumina-based sample (approximately 1 vs $100 \mathrm{~m}^{2} \mathrm{~g}^{-1}$, Fig. 8a, b). The catalytic behaviour of the samples is relatively similar in terms of conversion as a function of temperature as well as activation energies (Fig. 8d, e). This is surprising considering that only a fraction of the nominally substituted Rh exsolved on the surface of the perovksite, as shown above (see Fig. 6c, d) and in spite of having slightly different metal particle size distribution (Fig. 8c). The apparent higher activity of the exsolved particles might be due to their strained nature as shown previously for other exsolved metal particles ${ }^{37}$.

\section{Conclusions}

In an effort to efficiently use Rh we study its exsolution from dilute compositions and assess the parameters that affect it. We employ a Ca-based titanate knowing that Ca promotes lower temperature phase formation and ion diffusion which allowed us to prepare a perovskite with relatively small grain size $(\sim 500 \mathrm{~nm})$ which assists exsolution by decreasing the diffusional distance which ions need to travel in order to exsolve at the surface.

We test the effect of doping concentration, reduction time and reduction temperature on the characteristics of exsolved particles. Particle size increases with decreasing substitution level while particle population decreases probably because at dilute levels of doping nucleation becomes more difficult. Increased reduction times favour the diffusion of $\mathrm{Rh}$ atoms across the lattice which allows to exsolve from deeper and increase particle density, indicating that as opposed to samples prepared by deposition method where over time agglomeration occurs, here particles do not grow by agglomeration but rather by incorporation of newly exsolved atoms in the Rh clusters nucleated at the early stages of reduction. Increase in the reduction temperature causes an increase in the particle population up to $700{ }^{\circ} \mathrm{C}$ and then a decrease, while particle size grows with temperature. Applying these systems for $\mathrm{CO}$ oxidation showed that interestingly, activity is governed by a combination of particle size and population factored together through Rh coverage on the materials' surface.

The dilute exsolved materials prepared in this study exhibit similar activity profiles to conventionally used $\mathrm{Rh} / \mathrm{Al}_{2} \mathrm{O}_{3}$ with the 

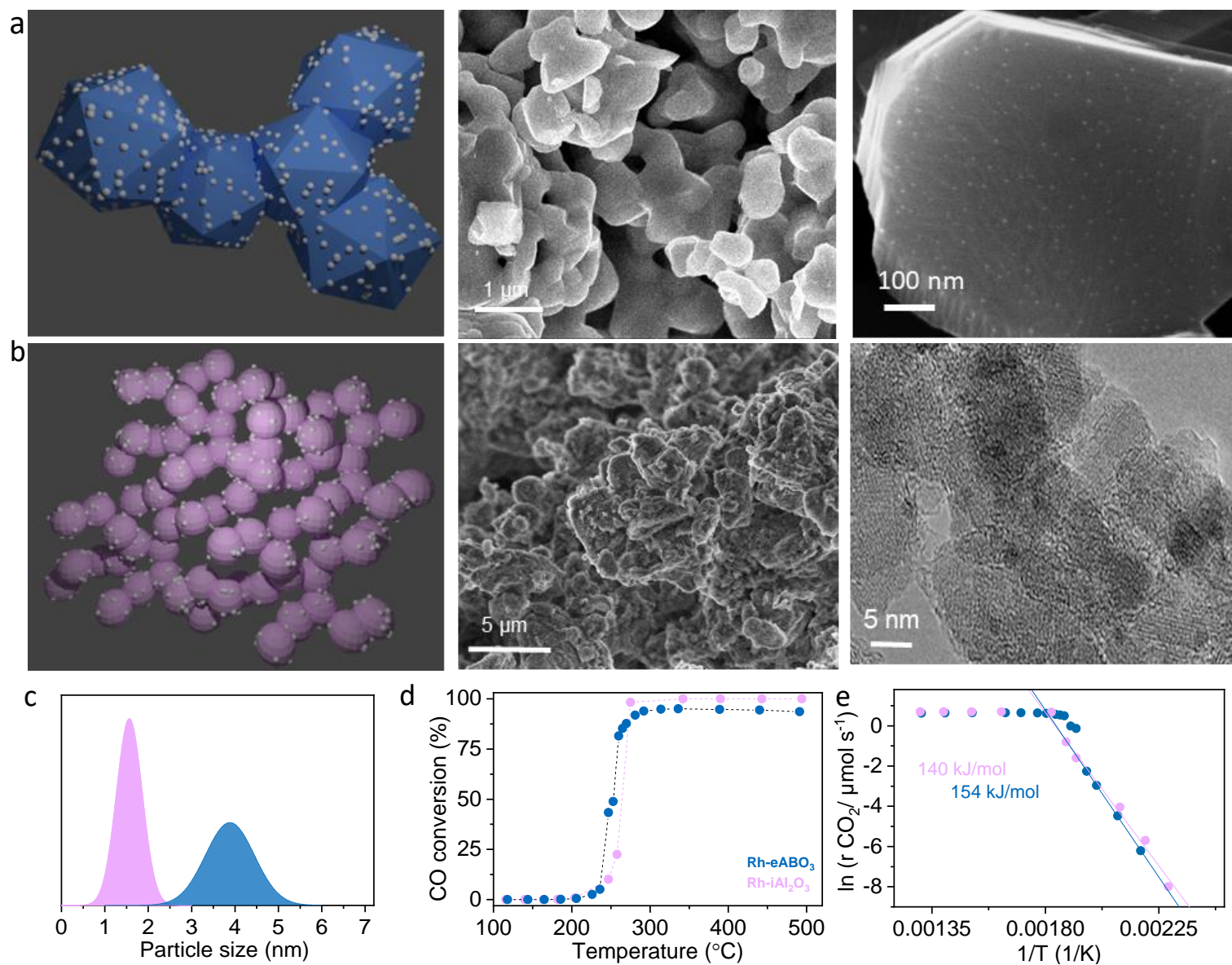

Fig. 8 Comparing Rh exsolved samples to impregnated samples with same Rh metal content. (a) Schematic representation, SEM images; low-magnification overview and detail of the surface and nanostructure of the Rh exolved sample $\left(\mathrm{T}_{\mathrm{R}}=900{ }^{\circ} \mathrm{C} \mathrm{Rh}_{-} \mathrm{eABO}\right)$. (b) $\mathrm{Schematic}$ representation, SEM and TEM images; low-magnification overview and detail of the surface and nanostructure of the Rh impregnated alumina $\left(\mathrm{Rh}-\mathrm{iAl}_{2} \mathrm{O}_{3}\right.$ ). (c) $\mathrm{Rh}$ particle size distribution on $\mathrm{La}_{0.43} \mathrm{Ca}_{0.37} \mathrm{Rh}_{0.01} \mathrm{Ti}_{0.99} \mathrm{O}_{3-\delta}$ and impregnated $\mathrm{Rh} / \mathrm{Al}_{2} \mathrm{O}_{3}$. (d) Catalytic activity in $\mathrm{CO}$ oxidation measured by $\mathrm{CO}$ conversion with temperature. (e) Arrhenius plots and activation energies calculated for (b).

same nominal loading, even though, as shown above, only about one tenth of the substituted Rh exsolved at the surface. This implies that not only exsolution from dilute compositions is feasible but also that it benefits from its previously demonstrated emergent functionalities, such as confinementenhanced activity.

\section{Conflicts of interest}

There are no conflicts to declare.

\section{Data availability}

The data supporting this publication is available at DOI: $10.25405 /$ data.ncl.8323604.

\section{Acknowledgements}

The research leading to these results has received funding from the European Research Council under the European Union's Seventh Framework Programme (FP/2007-2013) / ERC Grant
Agreement Number 320725 and from the EPSRC via grants EP/P007767/1, EP/P024807/1 and EP/R023921/1.

\section{References}

1 S. Wang, A. Chen, Z. Zhang and J. Peng, Environmental Progress \& Sustainable Energy, 2014, 33, 913-917.

2 C.-H. Kim, S. I. Woo and S. H. Jeon, Ind. Eng. Chem. Res., 2000, 39, 1185-1192.

3 X. Xie, Y. Li, Z.-Q. Liu, M. Haruta and W. Shen, Nature, 2009, 458, 746-749.

4 C. Tang, J. Li, X. Yao, J. Sun, Y. Cao, L. Zhang, F. Gao, Y. Deng and L. Dong, Applied Catalysis A: General, 2015, 494, 77-86.

5 R. Prasad and P. Singh, Catalysis Reviews, 2012, 54, 224-279.

6 X. Wang, K. Huang, L. Yuan, S. Xi, W. Yan, Z. Geng, Y. Cong, Y. Sun, H. Tan, X. Wu, L. Li and S. Feng, J. Phys. Chem. Lett., 2018, 9, 4146-4154.

7 Y. Nishihata, J. Mizuki, T. Akao, H. Tanaka, M. Uenishi, M. Kimura, T. Okamoto and N. Hamada, Nature, 2002, 418, 164167.

8 D. Neagu, E. I. Papaioannou, W. K. W. Ramli, D. N. Miller, B. J. Murdoch, H. Ménard, A. Umar, A. J. Barlow, P. J. Cumpson, J. T. S. Irvine and I. S. Metcalfe, Nature Communications, 2017, 8, 1855. 
9 E. I. Papaioannou, D. Neagu, W. K. W. Ramli, J. T. S. Irvine and I. S. Metcalfe, Topics in Catalysis, , DOI:10.1007/s11244-018-10538.

10 D. Neagu, T.-S. Oh, D. N. Miller, H. Ménard, S. M. Bukhari, S. R. Gamble, R. J. Gorte, J. M. Vohs and J. T. S. Irvine, Nature Communications, 2015, 6, 8120.

11 Y. Gao, J. Wang, Y.-Q. Lyu, K. Lam and F. Ciucci, J. Mater. Chem. A, 2017, 5, 6399-6404.

12 H. Tanaka, M. Taniguchi, M. Uenishi, N. Kajita, I. Tan, Y. Nishihata, J. Mizuki, K. Narita, M. Kimura and K. Kaneko, Angewandte Chemie International Edition, 2006, 45, 5998-6002.

13 H. Tanaka, M. Uenishi, M. Taniguchi, I. Tan, K. Narita, M. Kimura, K. Kaneko, Y. Nishihata and J. Mizuki, Catalysis Today, 2006, 117, 321-328.

14 H. Arandiyan, Y. Wang, J. Scott, S. Mesgari, H. Dai and R. Amal, ACS Appl. Mater. Interfaces, 2018, 10, 16352-16357.

15 Y. Gao, D. Chen, M. Saccoccio, Z. Lu and F. Ciucci, Nano Energy, 2016, 27, 499-508.

16 J. Y. Park, Y. Zhang, M. Grass, T. Zhang and G. A. Somorjai, Nano Lett., 2008, 8, 673-677.

17 A. V. Kalinkin, A. V. Pashis and V. I. Bukhtiyarov, 7.

18 B. H. Toby and R. B. Von Dreele, J Appl Cryst, 2013, 46, 544-549.

19 C. Mallika, M. Sreedharan and M. S. Chandrasekharaiah, 10.

20 P. A. Connor, X. Yue, C. D. Savaniu, R. Price, G. Triantafyllou, M. Cassidy, G. Kerherve, D. J. Payne, R. C. Maher, L. F. Cohen, R. I. Tomov, B. A. Glowacki, R. V. Kumar and J. T. S. Irvine, Advanced Energy Materials, 2018, 8, 1800120.

21 C. E. Vallet, A. Choudhury, P. E. Sobol and C. W. White, Electrochimica Acta, 1993, 38, 1313-1320.

22 V. I. Nefedov, M. N. Firsov and I. S. Shaplygin, Journal of Electron Spectroscopy and Related Phenomena, 1982, 26, 65-78.

23 M. T. Greiner, M. G. Helander, W.-M. Tang, Z.-B. Wang, J. Qiu and Z.-H. Lu, Nature Materials, 2012, 11, 76-81.

24 T.-S. Oh, E. K. Rahani, D. Neagu, J. T. S. Irvine, V. B. Shenoy, R. J. Gorte and J. M. Vohs, The Journal of Physical Chemistry Letters, 2015, 6, 5106-5110.

25 K. J. Kim, H. Han, T. Defferriere, D. Yoon, S. Na, S. J. Kim, A. M. Dayaghi, J. Son, T.-S. Oh, H. M. Jang and G. M. Choi, J. Am. Chem. Soc., 2019, 141, 7509-7517.

26 A. L. Borer and R. Prins, Journal of Catalysis, 1993, 144, 439451.

27 Y. Gao, Z. Lu, T. L. You, J. Wang, L. Xie, J. He and F. Ciucci, J. Phys. Chem. Lett., 2018, 9, 3772-3778.

28 D. Neagu, G. Tsekouras, D. N. Miller, H. Ménard and J. T. S. Irvine, Nature Chemistry, 2013, 5, 916-923.

29 D. A. J. M. Ligthart, R. A. van Santen and E. J. M. Hensen, Angewandte Chemie International Edition, 2011, 50, 5306-5310.

30 S. Cimino, L. Lisi, S. De Rossi, M. Faticanti and P. Porta, Applied Catalysis B: Environmental, 2003, 43, 397-406.

31 L. Simonot, F. Garin and G. Maire, Applied Catalysis B: Environmental, 1997, 11, 167-179.

32 P. Ciambelli, S. Cimino, S. De Rossi, L. Lisi, G. Minelli, P. Porta and G. Russo, Applied Catalysis B: Environmental, 2001, 29, 239250.

33 S. Royer and D. Duprez, ChemCatChem, 2011, 3, 24-65.

34 A. Boubnov, A. Gänzler, S. Conrad, M. Casapu and J.-D. Grunwaldt, Top Catal, 2013, 56, 333-338.

35 J. I. Flege and P. Sutter, Phys. Rev. B, 2008, 78, 153402.

36 G. Munuera, A. Fernandez and A. R. Gonzalez-Elipe, in Studies in Surface Science and Catalysis, ed. A. Crucq, Elsevier, 1991, vol. 71, pp. 207-219.
37 B. Yan, Q. Wu, J. Cen, J. Timoshenko, A. I. Frenkel, D. Su, X. Chen, J. B. Parise, E. Stach, A. Orlov and J. G. Chen, Applied Catalysis B: Environmental, 2018, 237, 1003-1011. 